\title{
Produção In Vitro de Embriões Bovinos: Utilização de Diferentes Fontes de Gonadotrofinas na Maturação dos Oócitos ${ }^{1}$
}

\author{
Lia de Alencar Coelho ${ }^{2}$, César Roberto Esper ${ }^{3}$, Rafael Herrera Alvarez ${ }^{4}$, Roberta Vantini ${ }^{5}$, \\ Ivo Luis Almeida Junior ${ }^{5}$
}

\begin{abstract}
RESUMO - O presente trabalho foi conduzido com o objetivo de avaliar o efeito da utilização de diferentes fontes de gonadotrofinas para maturação in vitro dos oócitos bovinos fecundados e desenvolvidos in vitro sobre as taxas de clivagem (TC) e de blastocistos (TBL). Oócitos imaturos provenientes de ovários de vacas de abatedouro foram submetidos a maturação in vitro sob diferentes condições: meio TCM 199, acrescido de 10\% de soro de vaca em estro (SVE), aditivos, hepes, $\mathrm{NaHCO}_{3}$, piruvato de sódio, antibióticos (meio B-199), $20 \mathrm{UI} / \mathrm{mL}$ de PMSG e $10 \mathrm{UI} / \mathrm{mL}$ de hCG (PMSG/hCG) ou meio B-199, acrescido de $5 \mu \mathrm{g} / \mathrm{mL}$ de FSH e $5 \mu \mathrm{g} / \mathrm{mL}$ de LH (FSH/LH). Seguidos $24 \mathrm{~h}$ de cultura a $38,5^{\circ} \mathrm{C}$ em atmosfera com $5 \%$ de $\mathrm{CO}_{2}$, os oócitos maturos foram incubados com sêmen descongelado durante 18 a 21 horas. Após esse período, os oócitos foram transferidos para placas contendo microgotas de meio Ménezo suplementado com $10 \%$ de SVE e células epiteliais do oviduto bovino em suspensão, cobertas com óleo de silicone, os quais permaneceram em cultura por mais 9 dias. Os dados foram analisados pelo teste do Qui-quadrado. A TC e a TBL, para PMSG/hCG e FSH/LH, foram 60 e $13,9 \%$ e 61,2 e $10,6 \%$, respectivamente. Não houve diferença entre os tratamentos com relação a TC ou a TBL. Esses resultados sugerem que ambas as fontes de gonadotrofinas podem ser utilizadas para maturação in vitro dos oócitos fecundados e desenvolvidos in vitro.
\end{abstract}

Palavras-chave: bovinos, embrião, fecundação in vitro, gonadotrofinas, maturação in vitro, taxa de clivagem

\section{In Vitro Production of Bovine Embryos: Utilization of Different Gonadotropin Sources for In Vitro Maturation of Oocytes}

\begin{abstract}
This study aimed to evaluate the effect of different gonadotropin sources for in vitro maturation of bovine oocytes fertilized and developed in vitro on cleavage (CR) and blastocysts rates (BLR). The immature oocytes from slaughterhouse cows ovaries were matured in vitro under different conditions: TCM 199 medium with $10 \%$ eostrous cow serum (ECS), aditives, hepes, $\mathrm{NaHCO}_{3}$, sodium pyruvate, antibiotics (B-199 medium), $20 \mathrm{UI} / \mathrm{mL}$ PMSG and $10 \mathrm{UI} / \mathrm{ml} \mathrm{hCG} \mathrm{(PMSG/hCG)} \mathrm{or} \mathrm{B-199} \mathrm{medium} \mathrm{with} 5 \mu \mathrm{g} / \mathrm{mL}$ FSH and $5 \mu \mathrm{g} / \mathrm{mL} \mathrm{LH}(\mathrm{FSH} / \mathrm{LH})$. After 24 hours of culture at $38.5^{\circ} \mathrm{C}$ with $5 \% \mathrm{CO}_{2}$ in air the mature oocytes were incubated with frozenthawed semen for 18-21 hours. After this, the oocytes were transferred into microdroplets of Ménezo medium with 10\% ECS and bovine oviduct ephitelial cells (BOEC) in suspension and were further cultured for 9 days. The data were analyzed by chi-square test. The CR and BLR for PMSG/hCG and FSH/LH were 60 and $13.9 \%$ and 61.2 and $10.6 \%$, respectively. There was no difference between treatments regarding to $\mathrm{CR}$ and BLR. The results indicate that both gonadotropin sources can be used for in maturation medium of oocyte fertilized and developed in vitro.
\end{abstract}

Key Words: bovine, cleavage rate, embryo, gonadotropin, in vitro fertilization, in vitro maturation

\section{Introdução}

As condições de cultura in vitro para maturação dos oócitos são essenciais para a obtenção de resultados satisfatórios dentro do sistema de produção in vitro de embriões. Oócitos imaturos, quando removidos de seus folículos e mantidos em cultura in vitro, são capazes de sofrer maturação nuclear, sem qualquer estímulo hormonal(Pincus \& Enzmann, 1935). Entre- tanto, esses oócitos não são capazes de atingir o desenvolvimento completo até o estágio embrionário de pré-implantação, sob condições in vitro (LeibfriedRutledge et al., 1987).

A adição de gonadotrofinas e esteróides no meio de maturação, com a finalidade de propiciar a competência de desenvolvimento embrionário dos oócitos mamíferos, após a fecundação in vitro (FIV), tem sido largamente investigado porém os resultados são

\footnotetext{
${ }^{1}$ Projeto financiado pela FAPESP

2 Docente do Depto. de Zootecnia da Fac. de Zootecnia e Eng. de Alimentos - FZEA/USP. Av. Duque de Caxias Norte 225 - Pirassununga, SP - CEP: 13635-900. E.mail: liac@usp.br

3 Docente da Faculdade de Ciências Agrárias e Veterinárias - FCAVJ/UNESP. E.mail: cresper@fcav.unesp.br

4 Pesquisador do Centro de Genética e Reprodução Animal - Instituto de Zootecnia. E.mail: herrera@izsp.br

5 Técnico de laboratório da FCAVJ/UNESP. E.mail: almeidaj@fcav.unesp.br; rvantini@fcav.unesp.br
} 
contraditórios. Enquanto algumas pesquisas têm demonstrado que somente o FSH é suficiente para promover o desenvolvimento embrionário de oócitos imaturos após maturação e fecundação in vitro (Eyestone \& Boer, 1993), outras têm ressaltado o efeito benéfico somente do LH e/ou do estradiol (Fukui et al., 1982; Dominko \& First, 1992; Guler et al., 2000). Há grupos de pesquisadores que têm demonstrado o efeito sinérgico de ambos: gonadotrofinas (FSH e LH) e estradiol (Fukushima \& Fukui, 1985; Yang et al., 1993; Wang et al., 1997; Van De Leemput et al., 1999; Hasler, 2000). Outros grupos têm utilizado o PMSG (Pregnant mare serum gonadotropin) associado ao hCG (human chorionic gonadotropin) para indução da maturação dos oócitos (Garcia et al., 1995; Avery et al., 1995). Os resultados conflitantes provavelmente são decorrentes das concentrações e das diferentes fontes hormonais utilizadas, quer seja em relação as gonadotrofinas ou aos esteróides (Fukui \& Ono, 1989; Brackett et al., 1989; Yang et al., 1993; Elmileik et al., 1995).

Apesar de o efeito individual e sinérgico da gonadotrofinas e esteróides na maturação oocitária ter sido intensamente estudado, existem poucas informações sobre o efeito da utilização de diferentes fontes de gonadotrofinas para maturação in vitro.

O presente trabalho foi conduzido com o objetivo de avaliar a utilização de diferentes fontes de gonadotrofinas na maturação dos oócitos fecundados e desenvolvidos in vitro sobre as taxas de clivagem (TC) e blastocistos (TBL).

\section{Material e Métodos}

\section{Obtenção dos oócitos e maturação in vitro (MIV)}

Os ovários, colhidos de vacas provenientes de abatedouro, foram transportados para o laboratório, a temperatura ambiente $\left(25-30^{\circ} \mathrm{C}\right)$, e dentro de frascos de vidros contendo solução salina a $0,9 \%$, acrescidos de sulfato de gentamicina $(50 \mu \mathrm{g} / \mathrm{mL})$ e fungizon $(2,5 \mu \mathrm{g} / \mathrm{mL})$. No laboratório, os ovários foram lavados $(2 \mathrm{X})$ com solução salina a $0,9 \%$ e mantidos em banho-maria, a $34-35^{\circ} \mathrm{C}$. Os complexos cumulusoócitos (COCs), aspirados de folículos de 3-8 mm, foram colocados em placas de Petri (100 mm), contendo meio TCM 199 suplementado com Hepes $(25 \mathrm{mM})$, sulfato de kanamicina $(75 \mu \mathrm{g} / \mathrm{mL})$ e $10 \%$ de soro fetal bovino (SFB) inativado (meio H-199). Sob estereoscópio (aumento de 10 a 60X), os COCs foram visualizados, lavados duas vezes em meio H-199, e colocados em cultura por $24 \mathrm{~h}$, a $38,5^{\circ} \mathrm{C}$ em atmosfera com $5 \%$ de $\mathrm{CO}_{2}$, em meio de maturação suplementado com hormônios conforme os tratamentos.

O meio básico de maturação foi constituído de meio TCM 199, suplementado com aditivos $(1 \mu \mathrm{g} / \mathrm{mL}$ de vitamina $\mathrm{B}_{12}, 10 \mu \mathrm{g} / \mathrm{mL}$ de insulina, $500 \mu \mathrm{g} / \mathrm{mL}$ de álcool polivinil, $75 \mu \mathrm{g} / \mathrm{mL}$ de ácido ascórbico, $5 \mu \mathrm{g} / \mathrm{mL}$ de inositol, $100 \mu \mathrm{g} / \mathrm{mL}$ de acetato de sódio e de glicosamina), Hepes $(16,79 \mathrm{mM})$, bicarbonato de sódio (28,57 mM), piruvato de sódio $(2,73 \mathrm{mM})$, sulfato de kanamicina $(75 \mu \mathrm{g} / \mathrm{mL})$ e $10 \%$ de soro inativado de vaca no estro (meio B-199). Os oócitos (até 200 oócitos) foram colocados em placa de polipropileno (35 mm) contendo $3 \mathrm{~mL}$ de meio B-199 com $20 \mathrm{UI} / \mathrm{mL}$ de $\mathrm{PMSG}^{1}$ e $10 \mathrm{UI} / \mathrm{mL}$ de $\mathrm{hCG}^{2}$ (PMSG/hCG) ou 2,5 mL de meio B-199 com $5 \mathrm{mg} / \mathrm{mL}$ de $\mathrm{FSH}^{3}$ e $5 \mathrm{mg} / \mathrm{mL}$ de $\mathrm{LH}^{4}(\mathrm{FSH} / \mathrm{LH})$ e mantidos em incubadora com $5 \%$ de $\mathrm{CO}_{2}$ a $38,5^{\circ} \mathrm{C}$ durante $22-24 \mathrm{~h}$.

Preparo do sêmen e fecundação in vitro (FIV)

Para fecundação dos oócitos maturos utilizou-se sêmen congelado de um reprodutor da raça Nelore. O sêmen descongelado foi submetido ao procedimento de lavagem para eliminação do plasma seminal e diluidor do sêmen. Ao conteúdo de duas palhetas foram adicionados $5 \mathrm{~mL}$ de meio TALP, sem cálcio e glicose, suplementado com sulfato de gentamicina (TALP Ca free). Após duplas centrifugações (a $200 \mathrm{~g}$ durante 5 minutos), o sedimento foi ressuspenso em meio Tyrodes acrescido de albumina, lactato e piruvato (TALP) com cálcio e sem glicose, suplementado com sulfato de gentamicina (TALP-FIV), penicilamina, hipotaurina, epinefrina (TALP-FIV-PHE) e heparina $(30 \mu \mathrm{g} / \mathrm{mL})$, ajustando-se a concentração espermática para $25 \times 10^{6}$ células $/ \mathrm{mL}$. Para realização da fecundação, os oócitos foram retirados do meio de maturação, lavados em meio H-199 sem soro (3X) e posteriormente em meio TALP-FIV, e colocados nas placas de fecundação. A fecundação foi realizada em placas de cultura 4 fossas onde cada fossa continha

\footnotetext{
1 Sigma G-4877

2 Profasi - Serono

3 Pluset - Serono

${ }^{4}$ bLH-NOBL Biochimical Division Sioux Center
}

R. Bras. Zootec., v.31, n.3, p.1117-1121, 2002 
um volume final de $500 \mu \mathrm{L}$ de meio TALP-FIV-PHE com 50 a 80 oócitos ( $\sim 75$ oócitos). A concentração espermática em cada fossa foi de $5 \times 10^{6}$ células $/ \mathrm{mL}$. Os oócitos e sêmen foram incubados com $5 \% \mathrm{de} \mathrm{CO}_{2}$ a $38,5^{\circ} \mathrm{C}$, por um período de 18 a 21 horas.

Cultivo in vitro (CIV) e obtenção das células epiteliais do oviduto bovino (CEOB)

Os oócitos supostamente fecundados foram removidos do meio de fecundação, lavados em meio TALP-FIV (2X) e uma vez em meio Ménezo (B2) e transferidos para as placas contendo microgotas de $100 \mu \mathrm{L}$ de meio B2, suplementado com $10 \%$ de soro de vaca em estro (SVE) e uma suspenção de células epiteliais do oviduto bovino (CEOB), cobertas com óleo de silicone.

As CEOBs foram obtidas após dissecção do oviduto, raspagem e sucessivas lavagens das células em meioH-199. Seguido àúltima lavagem (meio B-199), o sedimento foi ressuspenso em meio B-199 e cultivado overnight, com $5 \%$ de $\mathrm{CO}_{2}$ em ar a $38,5^{\circ} \mathrm{C}$. Após vinte e quatro horas, $2 \mu \mathrm{L}$ de CEOB foram adicionados em cada microgota de desenvolvimento.

\section{Modelo experimental e análise estatística}

Os dados referentes às taxas de clivagem e de blastocistos foram analisados pelo teste do Quiquadrado. A taxa de clivagem foi definida como a porcentagem de oócitos que apresentaram a primeira divisão celular 24 horas após a inseminação in vitro e a taxa de blastocistos foi definida como a porcentagem de blastocistos produzidos a partir dos oócitos inseminados, nos dias sete, oito e nove de cultura após a inseminação in vitro.

\section{Resultados e Discussão}

Não houve diferença $(\mathrm{P}>0,05)$ com relação a taxa de clivagem e a taxa de blastocistos quando utilizou-se PMSG/hCG ou FSH/LH para maturação in vitro (MIV) de oócitos bovinos fecundados in vitro. As taxas de clivagem e de blastocistos foram de 60,0 e $13,9 \%$ e 61,2 e 10,6\%, para PMSG/hCG e FSH/LH, respectivamente (Tabela 1). Os resultados obtidos foram comparáveis àqueles obtidos por outros trabalhos que estudaram o papel dos hormônios na MIV, com relação à taxa de clivagem (Fukui \& Ono, 1989; Eyestone \& Boer, 1993) e a taxa de blastocistos (Fukui \& Ono, 1989). Entretanto, a produção de blastocistos do trabalho em questão foi baixa, quando comparada com outros trabalhos que utilizaram hormônios para MIV (Yang et al., 1993; Elmileik et al., 1995; Lee \& Fukui, 1996; Wang et al., 1997; Van De Leemput et al., 1999; Hasler, 2000). As prováveis razões para resultados contraditórios residem principalmente na natureza e concentração de gonadotrofinas e estrógenos utilizados, meios e condições de cultura, tanto para maturação dos oócitos (Fukui \& Ono, 1989; Olson et al., 1991; Dominko \& First, 1992; Yang et al., 1993; Elmileik et al., 1995; Lee \& Fukui, 1996) como para o desenvolvimento embrionário (Wang et al., 1997; Van De Leemput et al., 1999; Hasler, 2000). No presente trabalho a fonte de estrógeno utilizada foi o soro de vaca em estro (SVE), enquanto a maioria dos trabalhos que apresentou resultados satisfatórios de produção de embriões utilizou o estradiol 17-b (Yang et al., 1993; Elmileik et al., 1995; Lee \& Fukui, 1996). A adição de estradiol no meio de maturação tanto melhora a maturação nuclear, como promove a síntese do fator de crescimento do pronúcleo masculino em oócitos imaturos submetidos à maturação e fecundação (Fukui et al., 1982). A desvantagem do uso do soro de vaca no estro consiste na indefinição de seus componentes pois, além de conter estrógenos, o soro pode conter outras substâncias estimuladoras e/ou inibidoras da maturação oocitária. Além disso, o uso do SVE impossibilita o conhecimento exato da concentração hormonal utilizada e os resultados podem ser influenciados pela partida do soro.

As concentrações de FSH utilizadas, no presente estudo, foram diferentes daquelas utilizadas na maioria dos trabalhos. Enquanto foram utilizados $5 \mu \mathrm{g} / \mathrm{mL}$, outros trabalhos utilizaram concentrações de FSH que variaram de 0,5 a $25 \mu \mathrm{g} / \mathrm{mL}$ (Fukui \& Ono, 1989; Dominko \& First, 1992; Yang et al., 1993). No trabalho em questão, como a fonte de FSH utilizada (Pluset), além do FSH, contém pequeno percentual de LH, provavelmente a concentração de FSH no meio de cultivo tenha sido inferior a $5 \mu \mathrm{g} / \mathrm{mL}$. Em contra partida, tem havido um consenso na concentração de LH utilizada, que geralmente tem sido de $5 \mu \mathrm{g} / \mathrm{mL}$ (Fukui \& Ono, 1989; Dominko \& First, 1992; Yang et al., 1993). Algumas pesquisas têm demonstrado que, apesar de a utilização do LH no meio de cultura não afetar a maturação, a taxa de fecundação e a competência de desenvolvimento embrionário dos oócitos imaturos foram melhoradas (Moor \& Trounson, 1977; Dominko \& First, 1992). O LH parece ser mais importante para maturação in vitro que o FSH, pois, quando se comparou, separadamente,

\footnotetext{
R. Bras. Zootec., v.31, n.3, p.1117-1121, 2002
} 
Tabela 1 - Taxa de clivagem e produção de blastocistos a partir de oócitos bovinos maturados in vitro com meio B199 acrescido de 20 UI de PMSG e 10 UI de hCG (PMSG/hCG) ou com FSH $(5 \mu \mathrm{g} / \mathrm{mL})$ e LH $(5 \mu \mathrm{g} / \mathrm{mL})(\mathrm{FSH} / \mathrm{LH})$

Table 1 - Cleavage rate and blastocysts production from bovine oocytes matured in vitro with B199 plus 20 UI PMSG and 10 UI hCG (PMSG/hCG) or FSH $(5 \mu \mathrm{g} / \mathrm{mL})$ and $L H(5 \mu \mathrm{g} / \mathrm{mL})(\mathrm{FSH} / \mathrm{LH})$

\begin{tabular}{lccc}
\hline $\begin{array}{l}\text { Tratamentos } \\
\text { Treatments }\end{array}$ & $\begin{array}{c}\text { Oócitos }\left(\mathrm{N}^{\mathrm{o}}\right) \\
\text { Oocytes }(N .)\end{array}$ & $\begin{array}{c}\text { \% de clivados }\left(\mathrm{N}^{\mathrm{o}}\right) \\
\text { \% cleaved }\left(N^{\mathrm{o}}\right)\end{array}$ & $\begin{array}{c}\% \text { de blastocistos }\left(\mathrm{N}^{\mathrm{O}}\right) \\
\% \text { blastocysts }(N .)\end{array}$ \\
\hline PMSG/hCG & 638 & $60,0(383)$ & $13,9(89)$ \\
FSH/LH & 464 & $61,2(284)$ & $10,6(49)$ \\
Total & 1102 & $60,5(667)$ & $12,5(138)$ \\
\hline
\end{tabular}

Os valores encontrados para os diferentes tratamentos não diferiram entre si $(P>0,05)$ pelo teste do Qui-quadrado No difference between treatments $(P>.05)$ by Chi-square test.

o efeito do FSH e LH na maturação, Dominko \& First (1992) demonstraram que o LH promove maior taxa de blastocistos. Adicionalmente, Brackett et al. (1989) verificaram que oócitos imaturos ao serem submetidos à MIV com altas concentrações de LH purificado apresentaram melhor competência de desenvolvimento embrionário. Entretanto oócitos desnudos, ou seja, sem as células do "cumulus oophorus", não respondem ao LH, sugerindo que estas células seriam mediadoras do efeito do LH na MIV (Brackett \& Zuelke, 1993).

Embora não tenha havido diferença na taxa de blastocistos, houve uma tendência do tratamento com PMSG/hCG ser melhor do que o tratamento com FSH/LH (Figura 1). O PMSG, também conhecido como eCG (Equine Corionic Gonadotropin) é uma molécula glicoproteíca que exibe atividade tanto de FSH como de LH, embora a atividade predominante seja do FSH. Já o hCG, apresenta uma atividade biológica similar a do LH. Garcia et al. (1995) demonstraram a eficiência da utilização do PMSG associado ao hCG no meio de maturação durante a técnica de produção in vitro de embriões bovinos. Um grupo de pesquisadores dinamarqueses que outrora utilizavam o soro de vaca no estro (Greve \& Madison, 1991), atualmente tem utilizado o PMSG/ hCG para maturação in vitro dos oócitos bovinos (Avery et al., 1995; Avery et al., 2000).

Apesar de a adição de gonadotrofinas no meio de maturação promover um efeito benéfico na subsequente fertilização e desenvolvimento embrionário dos oócitos, independente da fonte utilizada, o mecanismo pelo qual esses hormônios atuam, simultânea ou separadamente, sob condições in vitro, tem recebido atenção especial. No entanto ainda não se conhece a concentração e a relação ideal para estas gonadotrofinas durante o processo de maturação oocitária e a competência de desenvolvimento embrionário dos oócitos maturados in vitro com hormônios, após fecundação.

\section{Conclusões}

A fonte de gonadotrofinas utilizada na maturação dos oócitos parece não interferir de maneira decisiva na produção de embriões fecundados in vitro. Portanto qualquer uma delas, PMSG/hCG ou FSH/LH, pode ser utilizada para promover a maturação in vitro dos oócitos bovinos.

\section{Literatura Citada}

AVERY, B.; BRANDENHÓFF, H.R.; GREVE, T. Development of in vitro matured and fertilized bovine embryos, cultured from days $1-5$ post insemination in either menezo-B2 medium or in HECM-6 medium. Theriogenology, v.44, p.935-945, 1995.

AVERY, B.; MELSTED, J.; GREVE, T. In vitro production of bovine embryos in na oxoid anaerojar ${ }^{\mathrm{TM}}$ designed for the growth of microorganisms. In: INTERNATIONAL CONGRESS ON ANIMAL REPRODUCTION, 14., 2000, Estocolmo. Anais.... Estocolmo, 2000. v.2. p. 182

BRACKETT, B.G.; YOUNIS, A.I.; FAYRER-HOSKEN, R.A. Enhanced viability after in vitro fertilization of bovine oocytes matured in vitro with high concentrations of luteinizing hormone. Fertility and Sterility, v.52, p.319-324, 1989.

BRACKETT, B.G.; ZUELKE, K.A. Analysis of factors involved in the in vitro production of bovine embryos. Theriogenology, v.39, p.43-64, 1993.

DOMINKO, T.; FIRST, N.L. Kinetics of bovine oocyte maturation allows selection for developmental competence and its affected by gonadotropins. Theriogenology, v.37, p.203, 1992.(Abstract)

ELMILEIK, A.M.A.; MAEDA, T.; TERADA, T. Higher rates of development into blastocyst following the in vitro fertilization of bovine oocytes matured in a medium supplement with the fluid from large bovine follicles. Animal Reproduction Science, v.38, p.85-96, 1995.

EYESTONE, W.H.; BOER, H.A. FSH enhances developmental potencial of bovine oocytes matured in chemically defined medium. Theriogenology, v.39, p.216, 1993. (Abstract) 
FUKUI, Y.; FUKUSHIMA, M.; TERAWAKI, Y. et al. Effect of gonadotropins, steroids and culture media on bovine oocyte maturation in vitro. Theriogenology, v.18, p.161$175,1982$.

FUKUI, Y.; ONO, H. Effects of sera, hormones and granulosa cells added to culture for in-vitro maturation, fertilization, cleavage and development of bovine oocytes. Journal of Reproduction and Fertility, v.86, p.501-506, 1989.

FUKUSHIMA, M.; FUKUI, Y. Effects of gonadotropins and steroids on the subsequent fertilizability extrafollicular bovine oocytes cultured in vitro. Animal Reproduction Science, v.9, p.323-332, 1985.

GARCIA, J.M.; COELHO, L.A.; ESPER, C.R. O uso de PMSG/ HCG na maturação in vitro de oócitos bovinos fecundados in vitro. In: CONGRESSO BRASILEIRO DE REPRODUÇÃO ANIMAL, 1995, Belo Horizonte. Anais.... Belo Horizonte: 1995. p. 403.

GREVE, T.; MADISON, V. In vitro fertilization in cattle: a review Reproduction, Nutrition and Development, v.31, p.147-157, 1991.

GULER, A.; POULIN, N.; MERMILLOD, M. et al. Effect of growth factors, EGF and IGF-I, and estradiol on in vitro maturation of sheep oocytes. Theriogenology, v.54, p.209-218, 2000.

HASLER, J.F. In vitro culture of bovine embryos in Ménézo's B2 medium with or coculture and serum: the normalcy of pregnancies and calves resulting from transferred embryos. Animal Reproduction Science, vs.60-61, p.81-91, 2000.

LEE, E.; FUKUI, Y. Synergistic effect of alanine and glycine on bovine embryos cultured in a chemically defined and animo acid uptake by in vitro-produced bovine morulae and blastocysts. Biology of Reproduction, v.55, p.1383-1389, 1996.

LEIBFRIED-RUTLEDGE, M.L., CRITSER, E.S, EYESTONE, W.H. et al. Development potential of bovine oocytes matured in vitro or in vivo. Biology of Reproduction, v.36, p.376-383, 1987.
MOOR, R.; TROUNSON, A.O. Hormonal and follicular factors affecting maturation of sheep oocytes in vitro and their subsequent developmental capacity. Journal of Reproduction and Fertility, v.49, p.101-109, 1977.

OLSON, S.E.; THOMAS, W.K., SEIDEL Jr, G.E. Effects of gonadotropins during in vitro maturation of bovine oocytes on subsequent embryonic development. Theriogenology, v.35, p.250, 1991 (Abstract)

PINCUS, G.; ENZMANN, E. The comparative behaviour of mammalian eggs in vivo and in vitro. Journal of Experimental Medicine, v.62, p.665-675, 1935.

VAN DE LEEMPUT, E.E.; VOS, P.L.A.M.; ZEINSTRA, E.C. et al. Improved in vitro embryo development using in vivo matured oocytes from heifers superovulated with a controlled preovulatory LH surge. Theriogenology, v.52, p.335-349, 1999.

WANG, S.; LIU, Y.; HOLYOAK, G.R. et al. The effects of bovine serum albumin and fetal bovine serum on the develoment of pre-and postcleavage-stage bovine embryos cultured in modified CR2 and M199 media. Animal Reproduction Science, v.48, p.37-45, 1997.

YANG, X.; JIANG, S.; FOOTE, R.H. Bovine oocyte development following different oocyte maturation and sperm capacitation procedures. Molecular Reproduction and Development, v.34, p.94-100, 1993. 